\title{
REPRESENTAÇÃO DAS MULHERES NEGRAS NO CURRÍCULO OFICIAL DE HISTÓRIA DA SECRETARIA DA EDUCAÇÃO DO ESTADO DE SÃO PAULO
}

\author{
Fernanda Gomes Françoso ${ }^{1}$, Maria de Fátima Salum Moreira ${ }^{2}$ \\ ${ }^{1}$ Universidade Estadual Paulista - FCT/UNESP, Mestrado em Educação, Presidente Prudente, SP. ${ }^{2}$ Universidade do \\ Oeste Paulista - UNOESTE, Mestrado em Educação, Presidente Prudente, SP. E-mail: \\ fernanda_gomes_ag@yahoo.com.br
}

\begin{abstract}
RESUMO
Apesar dos avanços conquistados pela teoria feminista e pelo movimento negro, que resultaram na promulgação da Lei no 10.639/03, tornando obrigatória a inclusão do ensino da história e cultura afrobrasileira nos currículos escolares, notamos ainda a invisibilidade de conteúdos que abordem criticamente as contribuições das mulheres negras, na constituição da sociedade brasileira. $O$ presente artigo, resultante de uma pesquisa de Mestrado em andamento, é de caráter documental e bibliográfico, analisando de forma qualitativa a presença de conteúdos relacionados às mulheres negras, no Currículo Oficial de História da Secretaria da Educação do Estado de São Paulo. Constatamos que, nas raras vezes em que as mulheres negras aparecem, no currículo, o tratamento didático caracteriza-se pela inferiorização de seu papel na sociedade e pela omissão das lutas e resistências contra as variadas formas de opressão sofridas.
\end{abstract}

Palavras-chave: Mulheres negras. Currículo de História. Representação.

\section{REPRESENTATION OF BLACK WOMEN IN THE HISTORY OFFICIAL CURRICULUM OF THE EDUCATION SECRETARIAT OF SÃO PAULO STATE}

\begin{abstract}
Despite the advances made by the feminist theory and the black movement, which resulted in the enactment of Law 10.639 / 03, making it mandatory to include the teaching of Afro-Brazilian history and culture in school curriculum, we have noted also the invisibility of content that address critically the contributions of black women in the constitution of Brazilian society. This article, resulting of a master's research in progress, has a documentary and bibliographical approach and analyzes qualitatively the presence of contents related to black women in the history official curriculum of the education secretariat of São Paulo State. We have noted that, on the rare occasions that black women appear in the curriculum, the didactic treatment is characterized by inferiorization of their role in society and by the omission of the struggles and resistances against various forms of oppression suffered.
\end{abstract}

Keywords: Black women; History Curriculum; Representation. 


\section{INTRODUÇÃO}

Os estudos das contribuições dos grupos minoritários e principalmente das mulheres negras, na constituição da história, são praticamente ausentes no currículo de História e no currículo escolar em geral. A omissão do conhecimento que aborda as mulheres negras, de seu papel como sujeitos históricos, na construção da sociedade e sua invisibilidade nos currículos e materiais didáticos escolares, ainda permanece, apesar dos avanços da teoria feminista, das questões raciais, das novas abordagens teóricas da História, as quais privilegiam a história dos grupos marginalizados, em nossa sociedade, e das propostas pedagógicas para o ensino de História, que preveem a inclusão e problematização de tais conteúdos nos currículos escolares. Torres Santomé (1995) afirma que os alunos e alunas das instituições escolares desconhecem os estudos sobre a história das mulheres e dos porquês de sua opressão e silenciamento.

São raras as vezes em que as mulheres negras são focalizadas nos currículos e, quando aparecem, estão sempre em papéis subalternos, secundários ou vitimizados, o que consequentemente pode desenvolver sentimentos de hostilidade, estereótipos e representações negativas. Para romper com essas abordagens reducionistas, é importante que o currículo escolar valorize a cultura ancestral que negros e negras trouxeram consigo, a partir das diásporas, das artes, da música, das técnicas, assim como ressalte a importância das mulheres negras em suas comunidades como mantenedoras da família e da religiosidade, superando a representação simplista que as associa unicamente pelo viés do contexto da escravidão.

É necessário que essas discussões se articulem às análises sobre as relações de poder e os discursos que criam estigmas e exclusões, com o objetivo de entender que tais discriminações não são naturais, mas construídas historicamente, acabando por inferiorizar e subjugar as mulheres negras. As consequências desses estereótipos - que Hall (2014) designa como regime dominante de representação - foram a reprodução e manutenção do racismo e a circulação de imagens enviesadas através dos meios de comunicação, das instituições sociais e dos discursos, as quais impactaram diretamente na instituição escolar. Em tal perspectiva, é imperioso romper com a visão hegemônica é androcêntrica, europeia, heterossexual e cristã, bem como com concepções binárias e fixas das identidades (BUTLER, 2005). As relações assimétricas de poder que configuram as injustiças e desigualdades sociais precisam ser articuladas com outros marcadores sociais, como classe, raça sexualidade e idade (LOURO, 1997). Entende-se que uma feminista branca que defende a igualdade entre homens e mulheres pode, por exemplo, oprimir cotidianamente sua empregada doméstica negra. 
O currículo escolar (envolvendo práticas docentes, propostas oficiais, livros didáticos, projetos e datas comemorativas) é um território de lutas e disputas pela definição sobre o que deverá ser ensinado, como e por quê. Necessita de constantes reflexões e críticas, frente à posição de servidão e submissão a que os negros e negras são frequentemente associados, invisibilizandose suas inúmeras histórias de resistência e luta.

O Governo do Estado de São Paulo disponibiliza aos docentes e alunos da Rede Estadual de Ensino os Cadernos do Professor e do Aluno, que se constituem como material didático, oferecendo suporte às práticas pedagógicas em sala de aula. O presente artigo tem como objetivo analisar de que forma as mulheres negras são representadas nos materiais didáticos de História da referida proposta curricular. Com o objetivo de melhor compreender a opressão sofrida pelas mulheres negras, na sociedade, está sendo empreendida esta pesquisa de cunho qualitativo, por meio de estudos e análises de obras didáticas para o ensino de História. Neste texto, são apresentados alguns resultados dos estudos e análises cujo foco está na abordagem dos conceitos de representação e estereótipo, confrontando-se tal teorização com a análise dos Cadernos do Professor e do Aluno (SÃO PAULO, 2014), referentes ao componente curricular de História, no Ensino Fundamental II (6으 ao 9o ano).

Nossa pretensão foi, de início, identificar as situações de aprendizagem que são propostas quando referidas à apresentação das mulheres negras, nos conteúdos imagéticos e textuais dos livros. Posteriormente, serão aprofundadas análises críticas quanto ao modo como essas mulheres são representadas do ponto de vista histórico e quais são os efeitos na aprendizagem das estratégias didáticas utilizadas.

\section{SOBRE O CONCEITO DE REPRESENTAÇÃO E ESTEREÓTIPO}

Para uma melhor compreensão da questão das representações das mulheres negras e seus mecanismos de identificação, classificação e estereotipagem, enfocaremos os conceitos de representação e estereótipo, os quais são fundamentais no processo de elaboração das representações que permeiam o imaginário social.

As representações são construídas historicamente e podem ser concebidas como o campo dos significados e símbolos que organizam a vida social de indivíduos e grupos. Em tal perspectiva, os aspectos psíquicos presentes em uma determinada coletividade são condizentes com a sua cultura e estão expressos em ritos, códigos, normas, instituições, discursos, imagens, textos, símbolos etc. Sob tal concepção, a construção da cultura e sociedade é atribuída ao papel ativo e consciente dos sujeitos, mesmo que a relatividade do papel da consciência seja considerado. Em 
Gomes, encontramos que a representação envolve percepção, identificação, reconhecimento, classificação, legitimação ou exclusão.

Podemos então inferir que a vida coletiva, como a vida psíquica dos indivíduos, faz-se de representações, ou seja, das figurações mentais de seus componentes. Os sistemas de representação são construídos historicamente; eles originam-se do relacionamento dos indivíduos e dos grupos sociais e, ao mesmo tempo, regulam esse relacionamento. (GOMES, 2003, p. 76).

Em outras vertentes explicativas, a ênfase na exposição do conceito não está na atuação intencional e consciente dos sujeitos. Giroux (1999), por exemplo, destaca que a linguagem e a representação expressam relações de conhecimento/poder, legitimadas no discurso da ciência e da objetividade, para silenciar, marginalizar e representar inadequadamente as mulheres (p. 82, 83). Hall (2014, p. 489), por sua vez, entende que a representação se encontra expressa nas linguagens que fazem parte de cada cultura. Para o autor, a representação é ambivalente e serve tanto para criar imagens positivas quanto negativas sobre algo ou alguém, além de estar sempre envolvida por questões de poder. Trata-se de uma forma de poder discursivo e hegemônico, envolvido na produção de conhecimento, de imagens, e que tem o poder de marcar e classificar.

A representação está intimamente ligada à questão do estereótipo. De acordo com Hall (2014), estereotipar significa reduzir, essencializar, naturalizar e fixar as diferenças. É o processo de reter características simples, associadas sobretudo a traços físicos, o que reduz a pessoa a esses traços, exagera-os e os simplifica. Isso fica evidente nas imagens produzidas sobre as negras e negros, onde são realçados seus lábios grossos, cabelos crespos, rosto e nariz grandes e assim sucessivamente (p. 470). As representações e estereótipos sobre a África, os africanos, os negros brasileiros e sua cultura foram construídos histórica e socialmente nos processos de dominação, colonização e escravidão (GOMES, 2012).

A imagem que circula na sociedade até os dias atuais sublinha o papel subalterno das mulheres negras. Essa concepção, que se origina no período da escravidão, continua no pósabolição. Recém-libertas, não Ihes restaram alternativas no mercado de trabalho e, sem assistência do governo, muitas se destinaram a trabalhar em casas de família. Por muito tempo, foram a maioria a ocupar os serviços de empregadas domésticas.

As representações não se restringem somente à imaginação das pessoas, adentram o espaço escolar e têm impacto real na formação das subjetividades dos estudantes. As mulheres negras ficaram por muito tempo ausentes dos currículos e materiais didáticos de História e das demais disciplinas e, quando surgiram, foram abordadas de maneira fetichizada, folclorizada, subalternizada e exótica. Na maioria das vezes, são tratadas a partir da colonização europeia, do 
período escravagista, predominantemente associado ao processo de violência, sofrimento e vitimização a que foram submetidas. Assim, apareceram como pano de fundo, sempre em relação ao branco, como vítima da escravidão e de maneira passiva em face das injustiças que sofriam.

Sua contribuição cultural, social, religiosa e política, na história da humanidade, suas variadas formas de resistência e a problematização da discriminação racial permaneceram por muito tempo omitidas nos conteúdos históricos e nas práticas pedagógicas. De acordo com Silva, Teixeira e Pacífico (2013), nos livros didáticos de diferentes disciplinas,

São particularmente comuns a sub-representação de personagens negras, sempre acompanhada da presença de brancas como representantes naturais da humanidade; o silêncio sobre as desigualdades raciais, bem como sobre particularidades culturais e contribuições das populações negras; a estereotipia e o estabelecimento de posições de subalternidade como singulares e naturais aos negros. (p. 134).

Ainda segundo os autores, grande parte dos livros didáticos, quando incorporaram a história das mulheres negras, as representaram como objeto, na posição de submissas, com hipersexualidade e sem possibilidade de ação. Logo, críticas severas por parte do movimento negro e das mulheres negras, em específico, contestaram tais representações e reivindicaram uma revisão profunda nos currículos, programas e livros didáticos escolares que colocavam as mulheres negras em situação de opressão, subserviência e humilhação.

Uma alternativa para que as representações depreciativas que circulam na escola sobre as mulheres negras sejam transpostas é questionar criticamente e desconstruir as imagens negativas carregadas de reducionismos que as associam a papéis subalternos e erotizados, por identificações positivas. Trabalhar não apenas com as perdas e opressões sofridas, mas com a riqueza de sua cultura e o valor de suas lutas, resistências e conquistas. A escola, como espaço privilegiado de socialização, produção e crítica de conhecimentos, necessita desenvolver propostas as quais permitam questionar e desconstruir discursos com base em estereotipias e preconceitos. Para isso, as práticas dos professores, o currículo e os livros didáticos de História e das demais disciplinas precisam ser questionados e constantemente reconstruídos ou reconfigurados, no sentido de problematizar e incorporar todas essas questões.

A produção de imagens e concepções positivas sobre as mulheres negras deve ser efetivamente colocada em prática não só pela instituição escolar, porém, igualmente por diversos sujeitos e instituições, como os meios de comunicação, o movimento negro e a sociedade, no geral. 
ANÁLISE DAS REPRESENTAÇÕES DAS MULHERES NEGRAS NOS CADERNOS DO ALUNO E DO PROFESSOR

Em 2007, a partir do resultado das avaliações externas (SAEB ${ }^{1}$, ENEM), o Governo do Estado de São Paulo elaborou metas, com o intuito de organizar melhor o sistema educacional. Nesse contexto, foi criado o programa "São Paulo Faz Escola", cuja preocupação era unificar o currículo escolar para todas as mais de cinco mil escolas do Estado. O programa é responsável pela implantação do Currículo Oficial do Estado de São Paulo, formatado em documentos que constituem orientações para o trabalho do professor em sala de aula, visando a garantir uma base comum de conhecimento e competências para todos os professores e alunos, a fim de que as escolas funcionem como uma rede, pautadas pelos mesmos objetivos. Desenvolver competências e habilidades, por meio da implantação de um material pedagógico ${ }^{2}$ unificado para os alunos e professores da rede estadual, é o objetivo do programa.

Os Cadernos do Professor e do Aluno (SÃO PAULO, 2014), organizados por disciplina/série (ano), são construídos a partir de Situações de Aprendizagem que orientam o trabalho pedagógico no ensino dos conteúdos disciplinares específicos e a aprendizagem dos alunos. Esses conteúdos, habilidades e competências são acompanhados de orientações para a gestão da aprendizagem em sala de aula e para a avaliação e a recuperação ${ }^{3}$.

No Ensino Fundamental II (6ำ ao 9a ano), o componente curricular de História é distribuído em oito cadernos, que apresentam, no total, sessenta e quatro situações de aprendizagem. Ao analisar todo o material, identificamos somente duas situações de aprendizagem nas quais aparecem referências às mulheres negras, especificamente nos volumes I e II do 8o ano.

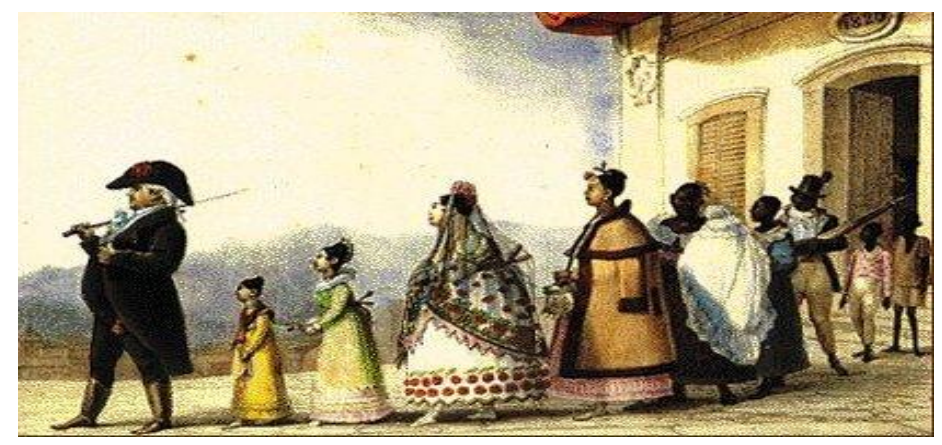

Jean-Baptiste Debret. Empregado do governo saindo a passeio, c. 1820/1830. Aquarela, 19 X 24,5 cm (MEA 226). Foto: Horst Merkel.

\footnotetext{
${ }^{1}$ Atualmente, Prova Brasil.

${ }^{2}$ A concepção do material é formulada por especialistas da Coordenadoria de Gestão da Educação Básica (CGEB).

${ }^{3}$ Informações extraídas dos portais eletrônicos da Secretaria Estadual da Educação de São Paulo (SEE/SP). http://www.educacao.sp.gov.br/saopaulo-faz-escola) e

http://www.rededosaber.sp.gov.br/portais/Default.aspx?alias=www.rededosaber.sp.gov.br/portais/spfe2009). Acesso em: 09/08/2015.
} 


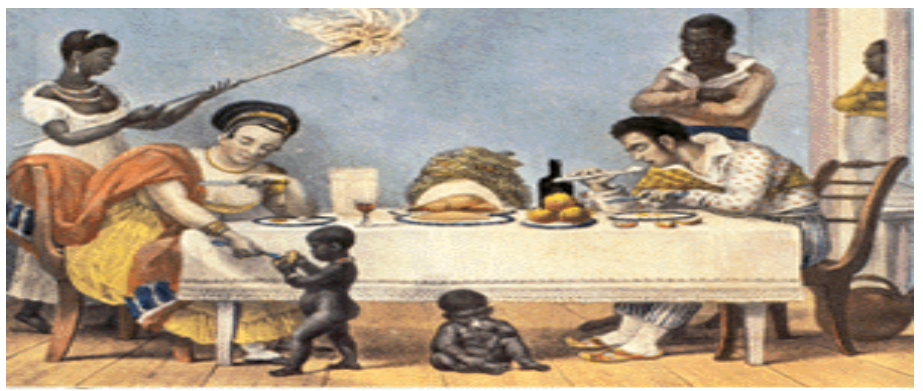

Jean-Baptiste Debret. Uma senhora de algumas posses em suas casas, 1823. Aquarela, 16,2 X 23cm (MEA 202). Foto: Horst Merkel.

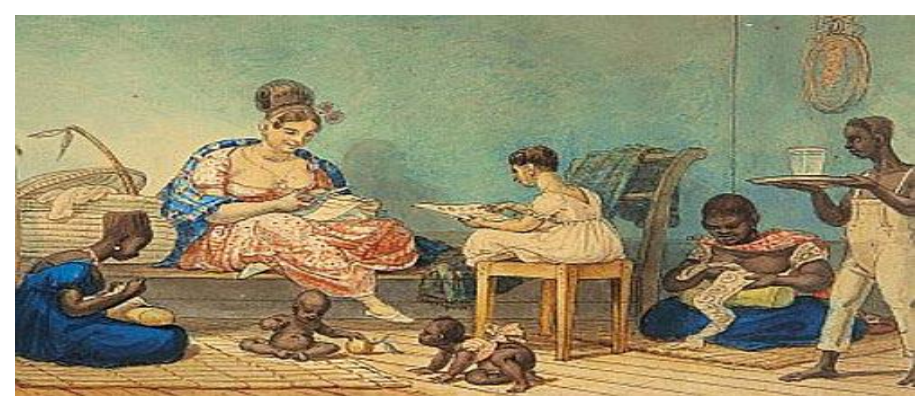

Jean-Baptiste Debret. Um jantar brasileiro, 1827. Aquarela, 15,7 X 21,9 cm (MEA 199). Foto: Horst Merkel.

No Caderno do Professor (SÃO PAULO, 2014c, p. 43), a situação de aprendizagem no 6 tem como objetivo analisar as imagens produzidas por Jean-Baptiste Debret, as quais constam em sua obra Viagem pitoresca e histórica ao Brasil (1834-1839), produzida como parte da Missão Artística Francesa patrocinada por D. João VI, no século XIX. No Caderno do Aluno (SÃO PAULO, 2014a, p. $58,59)$, há imagens representando as características da sociedade brasileira, no espaço público e privado. As mulheres negras escravas aparecem nas imagens como serviçais e acompanhantes de seus proprietários brancos. As atividades para os alunos interpretarem as imagens são perguntas de caráter descritivo. Na sequência, indica-se a elaboração de uma página de diário, onde os alunos precisam descrever, a partir das imagens, informações relacionadas à organização da sociedade, ao ambiente, aos objetos, aos personagens e suas ações, sua posição social e econômica. Não se propõe nenhuma reflexão aprofundada sobre a posição social das mulheres negras. As atividades seguintes referem-se a análises e questões sobre a abertura dos portos, o pacto colonial, o bloqueio continental, a vinda da Corte Portuguesa para o Brasil e os tratados entre o governo brasileiro e inglês. 


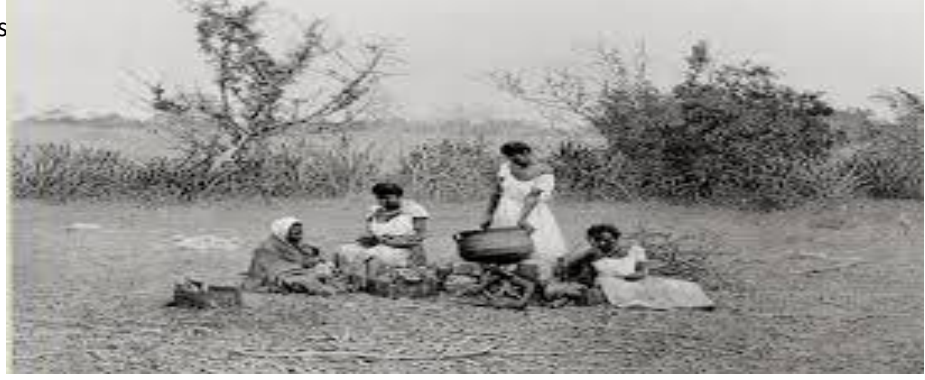

Escravas cozinhando na roça, 1858. Foto de Vitor e litografia de Benoist

No volume II do Caderno do Professor do 8o ano (SÃO PAULO, 2014d, p. 36), a situação de aprendizagem no 6 tem como objetivo a análise das leis promulgadas no Brasil, durante o Segundo Reinado, as quais contribuíram para a transição do trabalho escravo para o trabalho livre. No Caderno do Aluno (SÃO PAULO, 2014b, p. 40), vem uma litografia de 1858, intitulada "Escravas cozinhando na roça". Quatro mulheres negras escravas aparecem em uma paisagem natural, ao redor de uma base feita de madeiras e tijolos; uma mulher em pé segura uma panela sobre essa base, as outras três estão sentadas no chão, uma delas segurando uma criança, todas rodeadas com cestas e gravetos. As atividades para os alunos são perguntas relacionadas ao conceito de escravidão, ao trabalho escravo, às condições de vida e resistência dos escravos. No entanto, nenhuma atividade se associa à imagem e sua análise, propriamente dita. Não há reflexões e questionamentos utilizando como base a situação das mulheres negras.

As próximas atividades resumem-se a análises das leis sobre a extinção do tráfico negreiro, a do Ventre Livre, a da Libertação dos Sexagenários e a Lei Áurea. A presença da imagem fica descontextualizada, não apresentando qualquer relação com os conteúdos seguintes. As situações de aprendizagem terminam com indicações de bibliografias e revistas, mas nenhuma delas faz qualquer menção à história das mulheres negras. As mulheres que fizeram história, que lutaram e resistiram ao que Ihes foi imposto estão omitidas nos Cadernos. Dessa forma a história dessas mulheres fica reduzida ao período da escravidão e pode contribuir para cristalizar a ideia de que foram somente vítimas, serviçais e submissas, ao longo da história.

\section{CONCLUSÕES}

O currículo de História tem negligenciado os conteúdos que focalizam a história das mulheres negras e a sua colaboração para a história da sociedade, mesmo com as contribuições das teorias feministas, dos estudos sobre raça e das leis que estabelecem a sua obrigatoriedade.

Nas escassas vezes em que elas são contempladas na proposta curricular de História do Estado de São Paulo, estão relacionadas ao contexto da escravidão colonial, no Brasil, sendo frequentemente mostradas em papéis subalternos e subordinados. Há uma omissão quanto a sua 
contribuição e legado para a cultura afro-brasileira, o que pode cooperar para o desenvolvimento de estigmas, representações negativas e, consequentemente, sentimentos de discriminação e racismo. É necessário e urgente que tais documentos sejam revistos e que os professores tenham uma postura crítica diante dos conteúdos apresentados, a fim de construirmos uma educação mais justa e menos excludente.

\section{REFERÊNCIAS}

BUTLER, J. Problemas de gênero: feminismo e subversão da identidade. Estudos Feministas, Florianópolis, v. 13, n. 1, jan.-abr. 2005.

GIROUX, H. Cruzando as fronteiras do discurso educacional. Porto Alegre: Artes Médicas Sul, 1999.

GOMES, N.L. Cultura negra e educação. Revista Brasileira de Educação, n. 23, maio/jun./jul./ago. 2003.

GOMES, N.L. Relações étnico-raciais, educação e descolonização dos currículos. Currículo sem Fronteiras, v.12, n.1, p. 98-109, jan./abr. 2012.

HALL, S. Sin garantias: Trayectorias y problemáticas en estudios culturales. 2. ed. Universidad del Cauca, Envión, 2014.

LOURO, G.L. Gênero, sexualidade e educação: Uma perspectiva pós-estruturalista. Rio de Janeiro: Vozes, 1997.

SANTOMÉ, J.T. As culturas negadas e silenciadas no currículo. In: SILVA, T. T. Alienígenas na sala de aula: uma introdução aos estudos culturais em educação. Rio de Janeiro: Vozes, 1995.

SÃO PAULO (Estado) Caderno do Aluno. História: ensino fundamental. $8^{\circ}$ ano. Volume I. São Paulo: SEE, 2014a.

SÃO PAULO (Estado) Caderno do Aluno. História: ensino fundamental. $8^{\circ}$ ano. Volume II. São Paulo: SEE, 2014b.

SÃO PAULO (Estado) Caderno do Professor. História: ensino fundamental. $8^{\circ}$ ano. Volume I. São Paulo: SEE, 2014c.

SÃO PAULO (Estado) Caderno do Professor. História: ensino fundamental. $8^{\circ}$ ano. Volume II. São Paulo: SEE, 2014d.

SILVA, P.V.B., TEIXEIRA, R.; PACIFICO, T.M. Políticas de promoção de igualdade racial e programas de distribuição de livros didáticos. Educação e Pesquisa, São Paulo, v. 39, n. 1, p. 127-143, jan./mar. 2013. http://dx.doi.org/10.1590/S1517-97022013000100009 